Bolm Inst. oceanogr., S Paulo, 26:201-217, 1977

\title{
CICLO REPRODUTIVO E FLUTUAÇÃO ANUAL DA POPULAÇÃO DE JANAIRA GRACILIS (CRUSTACEA, ISOPODA, ASELLOTA)
}

\author{
ANA MARIA SETUBAL PIRES*
}

Instituto Oceanográfico da Universidade de São Paulo

\section{SYNOPSIS}

The life cycle and seasonal population changes of Janaira gracilis Moreira \& Pires, is studied in detail. J. gracilis is the most common isopod of the phytal fauna of Sargassum cymosum from Praia do Lamberto, Ubatuba, State of São Paulo (23030'S and 45007'W). The samples were collected once a month from January 1972 to January 1973. The data show a reproductive period continuous throughout the year with two peaks of major reproductive intensity. It is also discussed the populations characteristics and the sex ratio fluctuations.

\section{INTRODUÇÃO}

Alguns estudos sobre a biologia de Janaira gracilis Moreira \& Pires, vêm sendo realizados desde 1972, abordando aspectos do desenvolvimento (Pires, 1975; 1977) e da reprodução da espécie (Moreira \& Pires, 1977).

Janaira gracilis mostrou-se o isöpode mais abundante da fauna vágil de Sargassum cymosum da Enseada do Flamengo, Ubatuba, litoral norte do Estado de São Paulo, chegando a ser numericamente 50 vezes superior aos demais isópodes encontrados no mesmo local (Pires, 1975).

* Bolsista, Fundação de Amparo à Pesquisa do Estado de São Paulo (Proc. bio1. 71/1359). 
0 presente trabalho tem por objetivo o estudo do ciclo reprodutivo e das características gerais da população de Janaira gracilis, contribuindo assim para um maior conhecimento de sua biologia.

\section{MATERIAL E MÉTODOS}

Janaira gracilis foi coletada junto ao trapiche da Base Norte do Instituto Oceanogräfico da Universidade de São Paulo $\left(23^{\circ} 30^{\prime}\right.$ S e $\left.45^{\circ} 07^{\prime} \mathrm{W}\right)$, Ubatuba, litoral norte do Estado de São Paulo.

Amostras de Sargassum cymosum foram obtidas mensalmente, de janeiro de 1972 a janeiro de 1973. Em 1aboratório, o Sargassum foi lavado com água doce ligeiramente formalizada e os animais recolhidos, conservados em álcool 70\% para posterior retirada dos isópodes. Estes sofreram triagem sob microscópio estereoscópico sendo a população de Janaira gracilis separada em fêmeas, machos e jovens. As fêmeas foram classificadas em três categorias quanto ao seu desenvolvimento sexual:

- pré-ovígeras: portadoras de oostégitos em desenvolvimento nas bases dos pereópodos I-IV;

- ovígeras: carregando ovos ou embriões no marsúpio;

- pós-ovígeras ou esvaziadas: aquelas com marsúpio vazio e flácido.

Os machos foram classificados como tal a partir do 69 estädio de desenvolvimento pós-marsupial e do grupo dos jovens fazem parte os espécimens do 1 ọ ao 5 ọ estádio pós-marsupial (Pires, 1975).

A seguir, os exemplares sofreram contagem e mensuração. Após serem estendidos com auxílio de pinça, foram medidos do bordo mediano da cabeça ao ápice do pleotelson, com o emprego de câmara clara.

Dados ambientais foram tomados antes de cada coleta, com medidas de temperatura do ar, temperatura da água, oxigênio dissolvido e salinidade. 0 teor de oxigênio foi analisado pelo método de Winkler e a salinidade pelo de Harvey . 
A temperatura da água variou de $22,0^{\circ}$ a $28,5^{\circ} \mathrm{C}$, sendo as temperaturas mais elevadas encontradas de dezembro a abril (média de $27,3^{\circ} \mathrm{C}$ ) e as mais baixas de maio a novembro (média de $23,2^{\circ} \mathrm{C}$ ). Os valores de salinidade estiveram entre $31,2-35,4^{\circ} \%$ e os do oxigênio dissolvido na água entre 3,75$5,00 \mathrm{~m} 1 / 1$.

\section{CICLO REPRODUTIVO DE JANAIRA GRACILIS}

1. COMPOSIÇÃO ANUAL DA POPULAÇÃO DE FÊMEAS

0 estudo do ciclo reprodutivo de Janaira gracilis foi realizado através da distribuição porcentual dos três grupos da população de fêmeas (pré-ovígeras, ovígeras e pós-ovígeras) durante o período amostrado. A época de intensificação reprodutiva é expressa em termos de aumento na porcentagem de fêmeas ovígeras. Os três grupos estão presentes durante o ano todo, existindo uma proporção característica de cada um dentro da população (Tab. I, Fig. 1). 0 contingente maior pertence às fêmeas pré-ovígeras, freqüentemente excedendo os $50 \%$. Há flutuações mensais dentro de cada faixa, sendo as mais características as de dezembro/janeiro e julho/agosto. Em janeiro, tem-se o mínimo anual de fêmeas pré-ovígeras e o máximo de ovígeras, o que indica que a maior parte da população feminina encontra-se com ovos ou embriões no interior do marsúpio. A porcentagem de fêmeas ovígeras atinge o seu mínimo

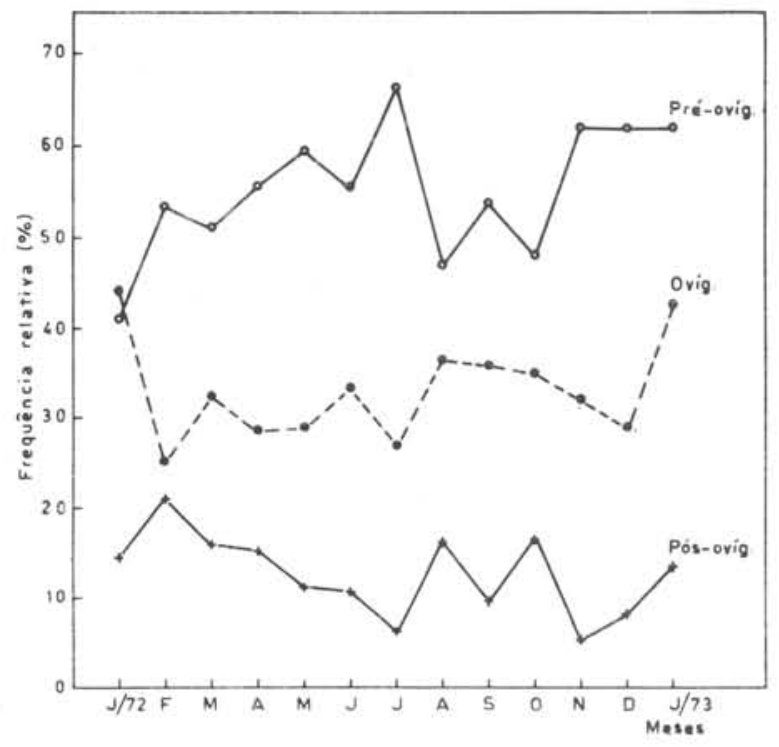

Fig. 1 - Distribuição anual da porcentagem de fêmeas prë-ovígeras, ovígeras e esvaziadas presentes mensalmente na população. 
TABELA I - Composição anual da população de fêmeas

\begin{tabular}{|l|r|r|r|r|r|r|r|}
\hline \multirow{2}{*}{ Mês } & \multicolumn{2}{|c|}{ Pré-ovígera } & \multicolumn{2}{|c|}{ Ovígera } & \multicolumn{2}{|c|}{ Pós-ovígera } & Tota1 \\
\cline { 2 - 7 } & \multicolumn{1}{|c|}{$\mathrm{N}$} & \multicolumn{1}{c|}{$\%$} & $\mathrm{~N}$ & \multicolumn{1}{c|}{$\%$} & $\mathrm{~N}$ & $\%$ & $\mathrm{~N}$ \\
\hline \multirow{2}{*}{ Jan./72 } & 119 & 41,46 & 126 & 43,90 & 42 & 14,63 & 287 \\
Fev. & 101 & 53,44 & 48 & 25,39 & 40 & 21,16 & 189 \\
Mar. & 306 & 51,25 & 195 & 32,66 & 96 & 16,08 & 597 \\
Abr. & 398 & 55,82 & 207 & 29,03 & 108 & 15,14 & 713 \\
Mai. & 153 & 59,53 & 75 & 29,18 & 29 & 11,28 & 257 \\
Jun. & 309 & 55,57 & 186 & 33,45 & 61 & 10,97 & 556 \\
Ju1. & 96 & 66,66 & 39 & 27,08 & 9 & 6,25 & 144 \\
Ago. & 46 & 46,93 & 36 & 36,73 & 16 & 16,32 & 98 \\
Set. & 55 & 53,92 & 37 & 36,27 & 10 & 9,80 & 102 \\
Out. & 55 & 48,67 & 39 & 34,51 & 19 & 16,86 & 113 \\
Nov. & 186 & 62,20 & 97 & 32,44 & 16 & 5,35 & 299 \\
Dez. & 104 & 62,27 & 49 & 29,34 & 14 & 8,38 & 167 \\
Jan. /73 & 109 & 43,60 & 107 & 42,80 & 34 & 13,60 & 250 \\
\hline N = Número absoluto de animais na amostra & & & \\
\hline
\end{tabular}

anual em fevereiro. De fevereiro a julho, cresce a porcentagem de fêmeas que se preparam para reprodução. Em julho, a maior parte da população de fêmeas é formada pelas pré-ovígeras, caindo relativamente bastante o número das duas outras classes. Em agosto, devido a um aumento na proporção de fêmeas ovígeras, hā novamente uma intensificação da reprodução, só que desta vez, em escala menọr do que em janeiro. De agosto a dezembro há muitas oscilações na porcentagem de fêmeas pré-ovígeras e esvaziadas, com tendência, no final do período, à elevação das primeiras e diminuição das últimas. A porcentagem de fêmeas ovígeras decresce gradualmente até dezembro. Em janeiro tem-se um outro aumento na reprodução, o que torna a composição da população seme1hante à descrita anteriormente para o mês de janeiro. 


\section{COMPRIMENTO DA FÊMEA PARA REPRODUÇÃO}

As menores fêmeas encontradas em reprodução durante o ano (ovígeras e esvaziadas) possuem um comprimento de $1,7 \mathrm{~mm}$, e as maiores, 3,3 mm. Exemplares entre 3,1-3,3 mm são em número bastante reduzido.

A maioria da população de fêmeas ovígeras está compreendida entre 2,0$2,5 \mathrm{~mm}$, com um comprimento médio de 2,2 mm (Tab. II, Fig. 2), havendo também fêmeas mais jovens $(1,9 \mathrm{~mm})$ e mais velhas $(2,6 \mathrm{~mm})$ reproduzindo-se ao mesmo tempo.

TABELA 11 - Distribuição do comprimento total de fêmeas ovígeras (com ovos e embriões), de janeiro de 1972 a janeiro de 1973

\begin{tabular}{|c|r|r|}
\hline $\begin{array}{c}\text { Comprimento } \\
\text { do corpo } \\
(\mathrm{mm})\end{array}$ & $\mathrm{N}$ & $\%$ \\
\hline 1,8 & 22 & 1,77 \\
1,9 & 58 & 4,68 \\
2,0 & 161 & 12,97 \\
2,1 & 206 & 16,60 \\
2,2 & 251 & 20,22 \\
2,3 & 195 & 15,71 \\
2,4 & 146 & 11,76 \\
2,5 & 102 & 8,22 \\
2,6 & 41 & 3,30 \\
2,7 & 32 & 2,58 \\
2,8 & 16 & 1,29 \\
2,9 & 5 & 0,40 \\
3,0 & 2 & 0,16 \\
3,1 & 2 & 0,16 \\
3,2 & 1 & 0,08 \\
3,3 & 1 & 0,08 \\
\hline $\mathrm{N}=$ Nümero absoluto de animais & na amostra \\
\hline
\end{tabular}


Da população total de fêmeas ovígeras (1241 indivíduos) foi retirada uma subamostragem de 270 exemplares com ovos e marsúpio fechado. Fazendo-se a distribuição mensal de seu comprimento (Tab. III, Fig. 3), verificou-se haver dois grupos principais de comprimento médio. 0 primeiro, de janeiro/72 a maio, possui as menores médias e não é tão homogêneo quanto o segundo, situado nos meses restantes. Fevereiro reune os indivíduos de menor comprimento, e portanto é nesse mês que estão as menores fêmeas em reprodução (as mais jovens). De junho a dezembro a população de fêmeas ovígeras é constituída por exemplares de maior comprimento, o que significa ser formada por indivíduos mais velhos. 0 valor encontrado em janeiro/73 mostrou-se intermediärio entre os dois grupos.

TABELA III - Comprimento de fêmeas ovígeras (com ovos e marsúpio fechado) durante $o$ ano

\begin{tabular}{|l|l|l|l|l|l|}
\hline \multicolumn{1}{|c|}{ Mes } & N & A & $\bar{x}$ & s & I $\bar{x}$ \\
\hline Jan./72 & 16 & $2,0-2,5$ & 2,23 & 0,157 & $2,14-2,31$ \\
Fev. & 39 & $1,8-2,5$ & 1,98 & 0,168 & $1,92-2,03$ \\
Mar. & 24 & $1,9-2,5$ & 2,09 & 0,150 & $2,02-2,15$ \\
Abr. & 48 & $1,9-2,6$ & 2,15 & 0,164 & $2,10-2,19$ \\
Mai. & 13 & $2,0-2,4$ & 2,18 & 0,107 & $2,12-2,24$ \\
Jun. & 22 & $2,1-2,7$ & 2,37 & 0,151 & $2,30-2,43$ \\
Jul. & 13 & $2,2-3,1$ & 2,45 & 0,240 & $2,30-2,59$ \\
Ago. & 24 & $2,2-2,6$ & 2,32 & 0,170 & $2,39-2,25$ \\
Set. & 11 & $2,1-2,7$ & 2,40 & 0,194 & $2,27-2,52$ \\
Out. & 12 & $2,2-2,8$ & 2,40 & 0,195 & $2,27-2,52$ \\
Nov. & 22 & $2,1-2,7$ & 2,38 & 0,195 & $2,30-2,47$ \\
Dez. & 10 & $2,3-3,0$ & 2,45 & 0,260 & $2,27-2,63$ \\
Jan./73 & 16 & $2,1-2,7$ & 2,31 & 0,170 & $2,22-2,40$ \\
\hline
\end{tabular}



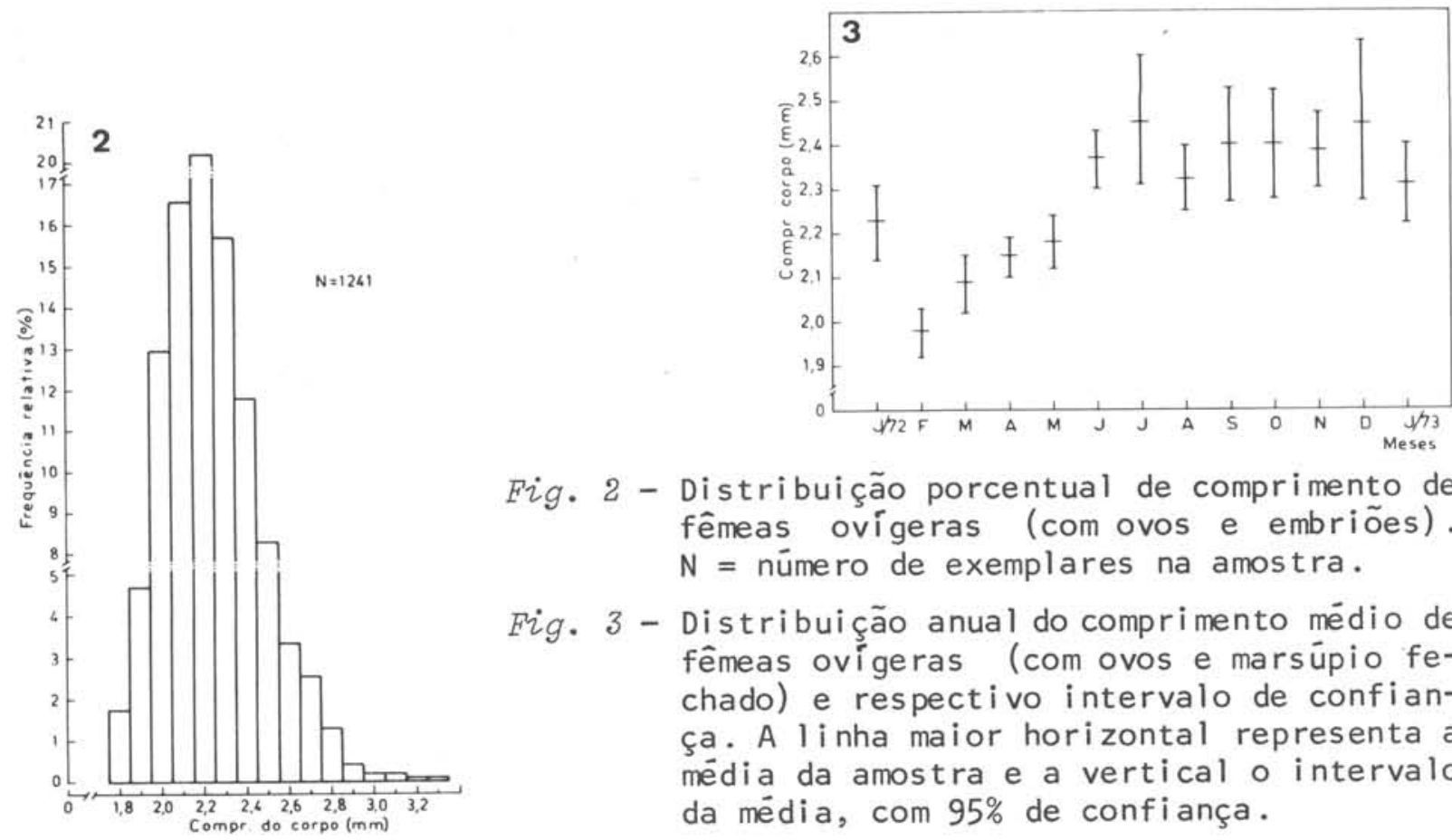

Fig. 2 - Distribuição porcentual de comprimento de fêmeas ovígeras (com ovos e embriões). $\mathrm{N}$ = número de exemplares na amostra.

Fig. 3 - Distribuição anual do comprimento médio de fêmeas ovígeras (com ovos e marsúpio fechado) e respectivo intervalo de confiança. A li nha maior horizontal representa a média da amostra e a vertical o intervalo da média, com $95 \%$ de confiança.

0 histograma construído com os dados de comprimento total das fêmeas esvaziadas também apresenta as mesmas características descritas acima (Fig. 4), o que vem confirmar os resultados obtidos para com as fêmeas ovígeras.

\section{CICLO REPRODUTIVO}

Conforme visto anteriormente, a maior parte das fêmeas que se reproduz de janeiro a maio possui comprimento relativamente pequeno. Este fato parece indicar que durante esse período a população deve estar em reprodução pela primeira vez. De julho a dezembro, com a continuação do crescimento, há fêmeas de maior comprimento reproduzindo-se novamente. Assim sendo, na porcentagem de fêmeas ovígeras de janeiro teríamos, na maioria dos casos, fêmeas mais jovens e reproduzindo-se pela primeira vez, enquanto que em agosto elas seriam mais velhas e o estariam fazendo pela segunda ocasião.

o maior número de fêmeas ovígeras encontradas nos primeiros meses do ano (Tab. I) provavelmente indica que muitas morram após a primeira gestação, tendo então um período de vida menor que aquelas que se reproduzem novamente. Como a moda das fêmeas esvaziadas tende a regredir para tamanhos menores de outubro em diante, supõem-se que as fêmeas com duas gestações vivam 
cerca de 10 meses, enquanto que aquelas com uma só gestação durem cerca de 6. Esta última suposição é baseada no comprimento médio da maioria dos animais esvaziados até junho (2,2 mm) (Fig. 4), comprimento este, que a partir dessa data, só tende a aumentar. As fêmeas de maiores comprimentos (maior ou igual a 3,0 mm) foram obtidas somente na segunda metade do ano, o que indica uma duração extrema de vida de cerca de 12 meses. Se a longevidade fosse maior, iríamos observar exemplares com grande comprimento o ano todo, o que, como vimos, não acontece.

\section{FLUTUAÇÃO ANUAL NA COMPOSIÇÃO MARSUPIAL}

0 marsúpio das fêmeas grávidas pode conter ovos ou embriões, classificados quanto ao seu desenvolvimento em quatro estádios (Pires, 1975):

- estádio A: ovos;

- estádio B: embrião envolto pela primeira membrana embrionária e com típico formato de vírgula;

- estádio C: embrião envolto pela segunda membrana embrionária, apresentando os apêndices formados;

- estádio D: embrião livre de membrana e morfologicamente semelhante ao adulto.

A distribuição mensal das porcentagens de fêmeas portadoras de ovos, embriões nos diversos estádios e esvaziadas pode ser observada na Figura 5. De um modo geral, picos de estádios consecutivos vão se sucedendo no decorrer dos meses. A um pico de fêmeas com ovos, segue-se um de fêmeas com embriões no estádio B, depois um nos estádios C e D e finalmente um pico de fêmeas esvaziadas. Durante todo o ano há liberação de jovens na população.

\section{FLUTUAÇÃO ANUAL DA POPULAÇÃO}

Fez-se a distribuição mensal do número de machos, fêmeas e jovens durante o período amostrado (Tab. IV, Fig. 6). Os dados indicam que a população de Janaira gracilis do trapiche é constituída por grande número de jovens, os quais, de março a dezembro, excedem os $50 \%$. Os adultos predominam 


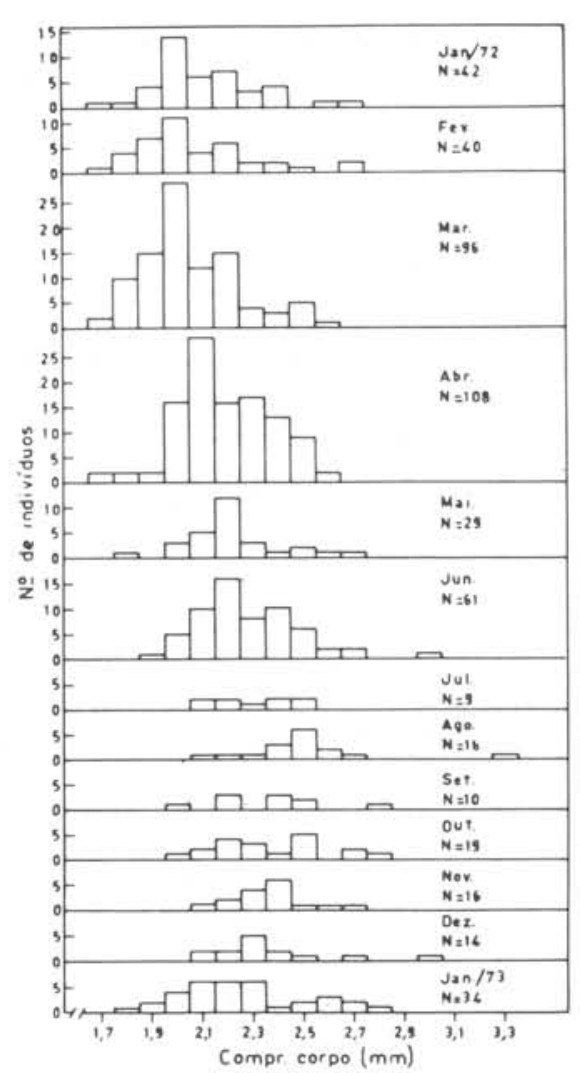

Fig. 4 - Histogramas mensais do comprimento de fêmeas esvaziadas, coletadas duranteo período amostrado. $\mathrm{N}=$ nümero de exemplares na amostra.

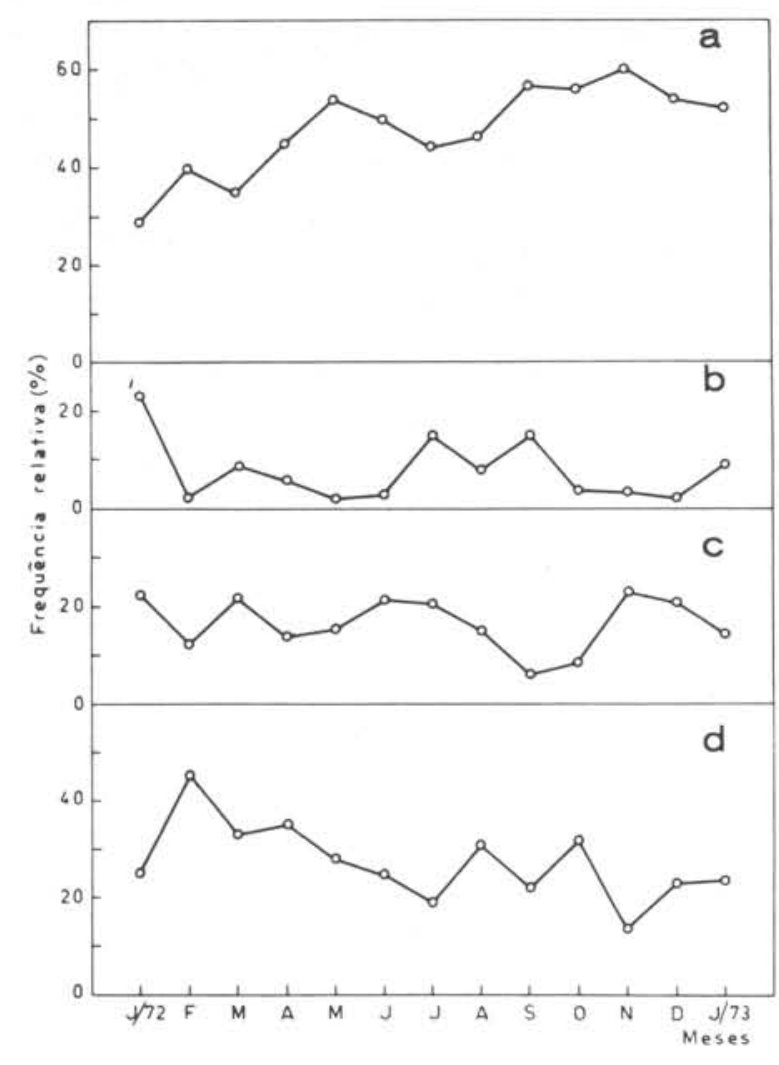

Fig. 5 - Flutuação anual na composição do marsūpio de fêmeas ovígeras e pós-ovígeras. (a) com ovos; (b) com embriões no marsúpio no estádio B; (c) com embriões nos estădios C e D; (d) com marsūpio vazio.

somente nos dois primeiros meses do ano. De março a junho e em novembro o número de indivỉduos é mais elevado que nos meses restantes, devido principalmente ao grande número de jovens presentes.

A distribuição mensal do comprimento da população está representada na Figura 7 e a proporção entre os sexos, na Tabela V e Figura 8. E difícil traçar o ciclo de vida de Janaira gracilis pois a reprodução é contínua e há jovens entrando na população durante o ano todo. Entretanto, o que pode ser observado é que em janeiro há uma intensificação reprodutiva primāria, e em abril e maio há grande número de jovens recém-saídos do marsúpio (comprimento entre 0,40 e 0,60 mm). Machos e fêmeas diferenciam-se com comprimentos entre 1,40 e 1,60 mm, porém os machos são em maior número (Fig. 7). De junho 
TABELA IV - Freqüência mensal de machos, fêmeas e jovens na população

\begin{tabular}{|c|c|c|c|c|c|c|c|}
\hline \multirow{2}{*}{ Mês } & \multicolumn{2}{|c|}{ Machos } & \multicolumn{2}{|c|}{ Fêmeas } & \multicolumn{2}{|c|}{ Jovens } & \multirow{2}{*}{$\begin{array}{c}\text { Total } \\
\text { N }\end{array}$} \\
\hline & $\mathrm{N}$ & $\%$ & $\mathrm{~N}$ & $\%$ & $\mathrm{~N}$ & $\%$ & \\
\hline Jan. /72 & 368 & 38,10 & 287 & 29,71 & 311 & 32,19 & 966 \\
\hline Fev. & 261 & 43,21 & 189 & 31,29 & 154 & 25,49 & 604 \\
\hline Mar. & 583 & 22,94 & 597 & 23,50 & 1361 & 53,56 & 2541 \\
\hline Abr. & 545 & 9,72 & 713 & 12,72 & 4345 & 77,54 & 5603 \\
\hline Mai. & 205 & 9,64 & 257 & 12,08 & 1665 & 78,27 & 2127 \\
\hline Jun. & 360 & 9,98 & 556 & 15,41 & 2691 & 74,60 & 3607 \\
\hline Jul . & 95 & 12,59 & 144 & 19,09 & 515 & 68,30 & 754 \\
\hline Ago. & 62 & 12,15 & 98 & 19,21 & 350 & 68,62 & 510 \\
\hline Set. & 108 & 16,16 & 102 & 15,27 & 458 & 68,56 & 668 \\
\hline Out. & 66 & 14,76 & 113 & 25,28 & 268 & 59,95 & 447 \\
\hline Nov. & 182 & 12,71 & 299 & 20,89 & 950 & 66,38 & 1431 \\
\hline Dez. & 149 & 16,70 & 167 & 18,72 & 576 & 64,57 & 892 \\
\hline Jan. /73 & 139 & 18,38 & 250 & 33,07 & 367 & 48,54 & 756 \\
\hline
\end{tabular}

em diante os machos tendem a se diferenciar com um comprimento maior $(1,60-$ $1,80 \mathrm{~mm}$ ). A partir de fevereiro o "sex-ratio" é favorável às fêmeas em taxa crescente, chegando em agosto a 1:1,6 (Tab. V). Neste mês tem-se uma intensificação reprodutiva secundária (Fig. 1). Em setembro há um aumento na proporção de machos e de outubro a dezembro a proporção de fêmeas começa a diminuir, tendendo a 1:1 em dezembro. Em janeiro/73 tem-se a taxa máxima de fêmeas encontradas no período estudado $(1: 1,8)$ ao lado de uma nova intensificação reprodutiva.

No período compreendido entre fevereiro e outubro, pode ser observado um aumento no número de machos e de fêmeas em março, junho e setembro, embora o "sex-ratio" seja favorāvel às fêmeas numa taxa crescente (com exceção do mês de setembro). Estes fatos mostram uma entrada de machos e fêmeas nesses três 

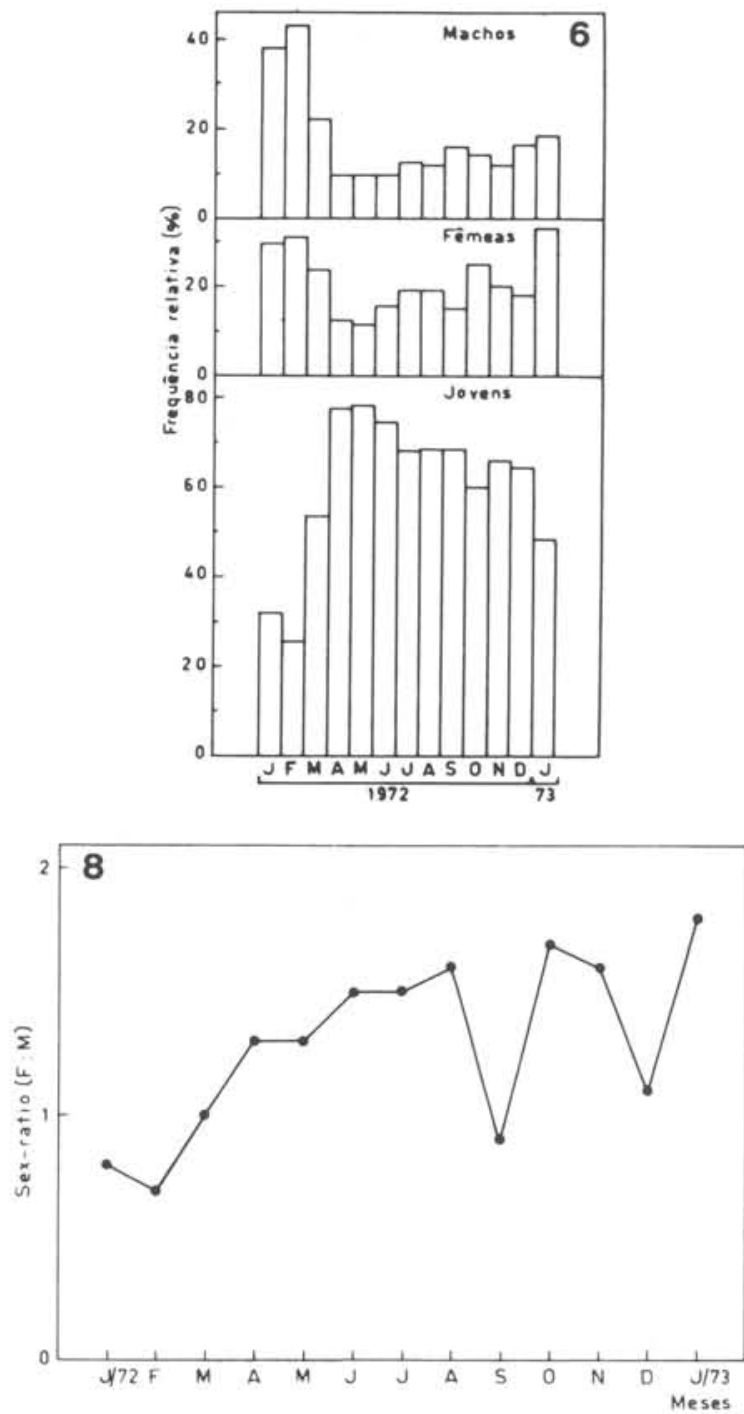

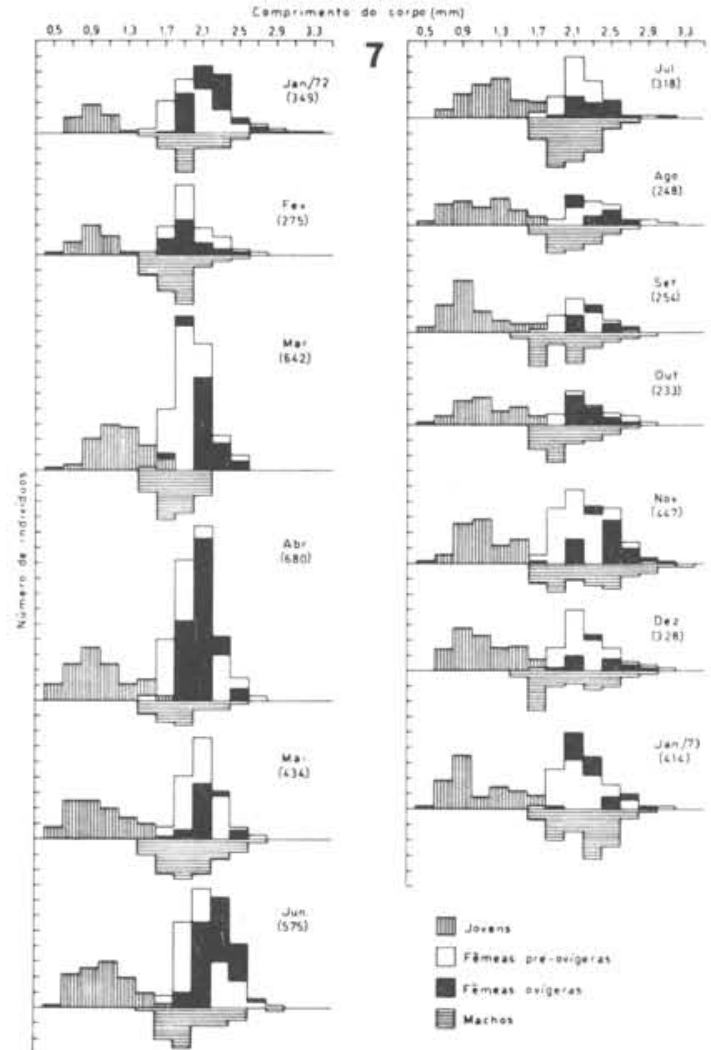

Fig. 6 - Histogramas da composição anual da população de Janaira gracilis, no período compreendido entre janeiro de 1972 e janeiro de 1973.

Fig. 7 - Distribuição mensal de comprimento da população de Janaira gracilis. N=nüme ro de exemplares na amostra.

Fig. 8 - Flutuação anual da proporção entre os sexos ("sex-ratio") na população estudada.

meses, sendo a quantidade de machos, no entanto, superior à de fêmeas somente em setembro. Em dezembro o número de machos e fêmeas, bem como a proporção entre eles, caem para valores mais baixos, indicando uma mortalidade em ambos os sexos. A brusca elevação da taxa de fêmeas observada em janeiro/ 73 sugere, nesse mês, uma mortalidade de machos aliada a uma grande entrada de fêmeas para a reprodução. 
TABELA V - Proporção entre os sexos na população de Janaira gracilis de Ubatuba, durante o período amostrado

\begin{tabular}{|c|c|c|c|c|c|}
\hline \multirow{2}{*}{ Mes } & Fêmeas & Machos & Total & Taxa & \multirow{2}{*}{$\mathrm{P}$} \\
\hline & $\mathrm{N}$ & $\mathrm{N}$ & N & Macho Fêmea & \\
\hline Jan. $/ 72$ & 287 & 368 & 665 & $1: 0,8$ & $<0,01$ \\
\hline Fev. & 189 & 261 & 450 & $1: 0,7$ & $<0,001$ \\
\hline Mar. & 597 & 583 & 1180 & $1: 1$ & $>0,05$ \\
\hline Abr. & 713 & 545 & 1258 & $1: 1,3$ & $<0,001$ \\
\hline Mai. & 257 & 205 & 462 & $1: 1,3$ & $<0,02$ \\
\hline Jun. & 556 & 360 & 916 & $1: 1,5$ & $<0,001$ \\
\hline Jul . & 144 & 95 & 239 & $1: 1,5$ & $<0,01$ \\
\hline Ago. & 98 & 62 & 160 & $1: 1,6$ & $<0,01$ \\
\hline Set. & 102 & 108 & 210 & $1: 0,9$ & $>0,05$ \\
\hline Out. & 113 & 66 & 179 & $1: 1,7$ & $<0,001$ \\
\hline Nov. & 299 & 182 & 481 & $: 1,6$ & $<0,001$ \\
\hline Dez. & 167 & 149 & 316 & $: 1,1$ & $>0,05$ \\
\hline Jan. $/ 73$ & 250 & 139 & 389 & $1: 1,8$ & $<0,001$ \\
\hline
\end{tabular}

\section{DISCUSSÃO}

A reprodução de Janaira gracilis é contínua durante o ano, com dois períodos de maior intensidade: janeiro e agosto. Este padrão era esperado (Thorson, 1950), já que a temperatura mostrou-se alta e relativamente constante durante todo o ano. Como se sabe, a temperatura é um dos fatores ambientais que nuito contribui para a caracterização do período de reprodução de uma espécie (Talin, 1970). 
Reproduçạo contínua tem sido relatada em muitas espécies de isópodes (Naylor, 1955; Daguerre de Hureaux, 1966; Talin, 1970; Amanieu, 1971) e parece ser vantajosa para as espécies que a possuem pois estas, geralmente, têm fecundidade baixa e taxa alta de mortalidade juvenil. Segundo Jansen (1971) esses dois fatores poderiam levar à diminuição progressiva da população durante o ano, o que tornaria menor a probabilidade de encontro entre os sexos e conseqüentemente, com o passar do tempo, a população poderia atingir níveis críticos para sua manutenção.

A falta de observações em laboratório impede-nos de saber qual o número de gerações por fêmea. Entretanto, baseados nos dados obtidos em campo, nos parece válida a suposição de que a maioria deva ter uma só gestação. 0 fato de que muitas fêmeas devam morrer após seu primeiro período reprodutivo deve-se ao fato de termos encontrado maior número de exemplares reproduzindo-se no início do ano, aliado à existência de um só pico máximo de comprimento para a desova $(2,2 \mathrm{~mm})$. Como observado anteriormente, na primeira intensificação reprodutiva do ano as fêmeas possuem um comprimento em torno de $2,0-2,1 \mathrm{~mm}$ e na segunda intensificação, ao redor de $2,4-2,5 \mathrm{~mm}$. Se todos os indivíduos que se reproduzem no primeiro período o fizessem também no segundo, teríamos dois picos de comprimento máximo para a desova, ao invés de um, e haveria uma porcentagem equivalente de fêmeas ovígeras nos dois grupos, o que não acontece $(29,55$ e $20,08 \%$, respectivamente) (ver Tab. II).

0 número extremamente baixo de fêmeas em reprodução acima dos $3,0 \mathrm{~mm}$ (3,0-3,3 mm) corresponde claramente a indivíduos no limite máximo de sua distribuição de comprimento, e que estão, provavelmente, na segunda ou mesmo terceira gestação. Pode ser também que animais desse grupo, tenham tido um amadurecimento sexual mais tardio que os outros indivíduos da mesma geração (Harvey, 1969).

Entre duas reproduções sucessivas a fêmea não deve passar por um período de repouso, pois não foram encontrados animais com comprimento superior a $1,80 \mathrm{~mm}$ sem oostégitos. Após a reprodução, a fêmea morre ou perde o marsúpio flácido, adquirindo oostégitos incipientes através da muda seguinte (Pires, 1975; Moreira \& Pires, 1977). Em Eugerda tetarda e Chelator insignis (Ase1lota) as fêmeas também entram em novo ciclo reprodutivo sem período de repouso, adquirindo oostégitos atravēs de muda, logo após a liberação dos jo- 
vens (Hessler, 1970). Segundo E11is (1961) o mesmo acontece com Asellus intermedius.

$\mathrm{Na}$ espécie em estudo a proporção entre os sexos não sofre grandes flutuações, embora a quantidade de fêmeas seja ligeiramente maior em nove meses dos 13 amostrados. Segundo Daguerre de Hureaux (1966), a proporção entre os sexos em quase todos os crustáceos é favorável às fêmeas, e há inúmeros exemplos deste fato em isópodes (Gebelin, 1939; Daguerre de Hureaux, 1966; Holdich, 1968; Talin, 1970; Jones \& Naylor, 1971). Em Janaira gracilis o "sex-ratio" é favorável aos machos nos períodos pós-reprodutivos (1:0,7 em fevereiro e 1:0,9 em setembro), o mesmo sendo encontrado por Jones (1974) em Jaera nordmanni nordica.

As flutuações de pequena amplitude observadas no "sex-ratio" de J. gracilìs sugerem uma razoável estabilidade na população, provavelmente causada pelo modo de reprodução contínuo da espécie e estabilidade das condições ambientais.

\section{CONCLUSÕES}

0 presente estudo possibilitou o conhecimento das seguintes características do ciclo biológico de Janaira gracilis:

1 - A reprodução é do modo contínuo, com dois períodos de intensificação reprodutiva: janeiro, quando a reprodução é máxima, e agosto, quando se desenvolve uma atividade secundāria.

2 - Esse tipo de reprodução fica evidenciado por:

- presença constante de fêmeas em todos os estádios de seu ciclo sexual;

- grande porcentagem de fêmeas pré-ovígeras durante o ano, freqüentemente excedendo os $50 \%$ da população;

- número elevado de jovens durante todo o período amostrado. 
3 - Hā uma diferença no comprimento médio mensal das fêmeas, sendo as menores encontradas no início do ano. A distribuição de comprimento das fêmeas ovígeras e esvaziadas sugere que a maioria se reproduz somente uma vez e morra após a primeira gestação.

4 - 0 período de vida da espécie, de acordo com o ciclo reprodutivo sugerido, foi estimado em cerca de seis meses para as fêmeas com uma gestação e 10 meses para as com duas. Nos maiores exemplares encontrados o período de vida pode ser estendido para cerca de 12 meses.

5 - A proporção entre os sexos não apresenta flutuações de grande amplitude, sendo favorável às fêmeas em nove meses dos 13 analisados.

\section{SUMMARY}

The life cycle and seasonal population changes of Janaira gracilis is considered in detail. J. gracilis is the most common isopod of the phytal fauna of Sargassum cymosum from Praia do Lamberto, Ubatuba, State of São Paulo.

Monthly samples of Janaira were collected at the pier of Base Norte, Instituto Oceanográfico, USP, from January 1972 to January 1973.

The reproductive period of the species is continuous throughout the year and two peaks of major reproductive intensity can be noted: the first one in January and the second in August. It is also discussed the number of generations by female.

The female seems to die after its first reproduction, but some may live longer, getting new oostegites at the next reproductive molt.

A population characteristic is the high number of juveniles. They are present all the year round increasing in number in April and May. The sexratio is favorable to the females during most of the year and shows small fluctuation. 


\section{AGRADECIMENTOS}

Agradeço ao Prof. Dr. Plínio Soares Moreira a revisão crítica do manuscrito. Sou também grata à Srta. Leko Kanno por cobrir os desenhos a nanquin.

\section{B IBLI OGRAFIA}

AMANIEU, M. 1971. Cycles reproducteurs et fécondité de quelques crustacés péracarides littoraux. Déterminisme écologique et comparaisons biogéographiques. Bul1. Stn biol. Arcachon, n.s., (23):223-232.

DAGUERRE DE HUREAUX, N. P. 1966. Étude du cycle biologique de Sphaeroma serratum au Maroc. Bull. Soc. Sci. nat. Maroc, 46(1-2):19-52.

ELLIS, R. J. 1961. A life history study of Asellus intermedius Forbes. Trans. Am. microsc. Soc., 80(1):80-102.

GEBELIN, F. 1939. Observations relatives a la sexualité de 1 'isopode oniscoide Ligia oceanica. Développement des oostegites. Bull. Soc. zool. Fr., 64:190-200.

HARVEY, C. E. 1969. Breeding and distribution of Sphaeroma (Crustacea: Isopoda) in Britain. J. Anim. Eco1., 38(2):399-406.

HESSLER, R. R. 1970. The Desmosomatidae (Isopoda, Asellota) of Gay Head-Bermuda Transect. Bul1. Scripps Instn Oceanogr., 15:1-185.

HOLDICH, D. M. 1968. Reproduction, growth and bionomics of Dynamene bidentata (Crustacea, Isopoda). J. Zool., 156:137-153.

JANSEN, K. P. 1971. Ecological studies on intertidal New Zealand Sphaeromatidae (Isopoda: Flabel1ifera). Mar. Bio1., 11:262-285.

JONES, M. B. 1974. Breeding biology and seasonal population changes of Jaera nordmanni nordica Lemercier (Isopoda, Asellota). J. mar. biol. Ass. U. K., 54:727-736.

\& NAYLOR, E. 1971. Breeding and bionomics of the Bristish members of the Jaera albifrons group of species (Isopoda: Asellota). J. Zool., $165(2): 183-199$.

MOREIRA, P. S. \& PIRES, A. M. S. 1977. Aspects of the breeding biology of Janaira gracilis Moreira \& Pires (Crustacea, Isopoda, Asellota). Bolm Inst. oceanogr., S Paulo, 26:181-199. 
NAYLOR, E. 1955. The life cycle of the isopod Idotea emarginata (Fabricius). J. Anim. Ecol., 24(2):270-281.

PIRES, A. M. S. 1975. Sobre a biologia de Janaira gracilis (Crustacea, Isopoda, Asellota) da fauna vágil de Sargassum cymosum. Dissertação de Mestrado. Universidade de São Paulo, Instituto Oceanográfico. 51 p., 10 tabs, 81 figs. (Não publicado).

naira gracilis 1977. Desenvolvimento marsupial e pos-marsupial de JaS Paulo, 26:21-50.

TALIN, J. 1970. Sur le cycle biologique de Sphaeroma hookeri Leach (Isopode flabellifère) dans les eaux de la Durançole (B. du Rh.). Hydrobiologia, 36(2):295-303.

THORSON, G. 1950. Reproductive and larval ecology of marine bottom invertebrates. Biol. Rev., 25(1):1-45.

(Recebido em 09/dezembro/1975) 